\title{
Review of friction modeling in metal forming processes
}

Nielsen, C.V.; Bay, N.

Published in:

Journal of Materials Processing Technology

Link to article, DOI:

10.1016/j.jmatprotec.2017.12.023

Publication date:

2018

Document Version

Peer reviewed version

Link back to DTU Orbit

Citation (APA):

Nielsen, C. V., \& Bay, N. (2018). Review of friction modeling in metal forming processes. Journal of Materials Processing Technology, 255, 234-241. https://doi.org/10.1016/j.jmatprotec.2017.12.023

\section{General rights}

Copyright and moral rights for the publications made accessible in the public portal are retained by the authors and/or other copyright owners and it is a condition of accessing publications that users recognise and abide by the legal requirements associated with these rights.

- Users may download and print one copy of any publication from the public portal for the purpose of private study or research.

- You may not further distribute the material or use it for any profit-making activity or commercial gain

- You may freely distribute the URL identifying the publication in the public portal

If you believe that this document breaches copyright please contact us providing details, and we will remove access to the work immediately and investigate your claim 


\section{Accepted Manuscript}

Title: Review of friction modeling in metal forming processes

Authors: C.V. Nielsen, N. Bay

PII:

DOI:

S0924-0136(17)30614-3

Reference:

https://doi.org/10.1016/j.jmatprotec.2017.12.023

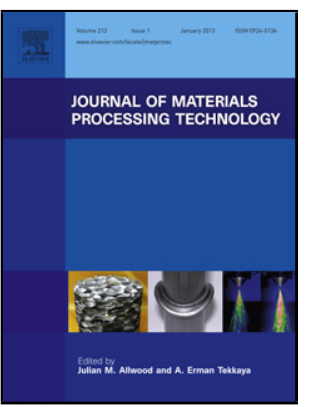

PROTEC 15560

To appear in: $\quad$ Journal of Materials Processing Technology

Received date: $\quad 31-10-2017$

Revised date: $\quad 11-12-2017$

Accepted date: $\quad$ 16-12-2017

Please cite this article as: Nielsen CV, Bay N, Review of friction modeling in metal forming processes, Journal of Materials Processing Technology (2010), https://doi.org/10.1016/j.jmatprotec.2017.12.023

This is a PDF file of an unedited manuscript that has been accepted for publication. As a service to our customers we are providing this early version of the manuscript. The manuscript will undergo copyediting, typesetting, and review of the resulting proof before it is published in its final form. Please note that during the production process errors may be discovered which could affect the content, and all legal disclaimers that apply to the journal pertain. 


\title{
Review of friction modeling in metal forming processes
}

\author{
Nielsen C.V. ${ }^{\mathrm{a}}$ and Bay N. ${ }^{\mathrm{b}}$ \\ ${ }^{a}$ Corresponding author. Department of Mechanical Engineering, Technical University of Denmark, Denmark \\ (cvni@mek.dtu.dk) \\ Produktionstorvet 425, 218 \\ DK-2800 Kgs. Lyngby \\ Phone: +4545254770 \\ ${ }^{b}$ Department of Mechanical Engineering, Technical University of Denmark, Denmark (nbay@mek.dtu.dk)
}

\begin{abstract}
In metal forming processes, friction between tool and workpiece is an important parameter influencing the material flow, surface quality and tool life. Theoretical models of friction in metal forming are based on analysis of the real contact area in tool-workpiece interfaces. Several research groups have studied and modeled the asperity flattening of workpiece material against tool surface in dry contact or in contact interfaces with only thin layers of lubrication with the aim to improve understanding of friction in metal forming. This paper aims at giving a review of the most important contributions during the last 80 years covering experimental techniques, upper bound solutions, slip-line analyses and numerical simulations. Each of the contributions shed light on the importance of the real contact area and the influencing parameters including the material properties, surface conditions, normal pressure, sliding length and speed, temperature changes, friction on the flattened plateaus and deformation of the underlying material. The review illustrates the development in the understanding of asperity flattening and the methods of analysis.
\end{abstract}

KEYWORDS: Metal forming tribology; Asperity flattening; Real contact area 


\section{INTRODUCTION}

The adhesion theory was the first quantitative theory on friction, which was proposed independently by three different research groups around 1940; namely Holm (1938), Ernst and Merchant (1940) and Bowden and Tabor (1942). The theory was based on analyzing the individual plastic deformation of contacting asperities between two metal surfaces and shearing due to adhesion and cold welding of the asperities. Bowden and Tabor observed that the linearity between normal pressure and friction in Amontons-Coulomb's model disappears when the normal pressure becomes large. A solution to this problem was proposed by Orowan (1943) in modeling of rolling by applying the shear flow stress as an upper limit. The present paper aims at providing a concise summary of the most important contributions since these early findings until the present state of the art of friction modeling in metal forming.

\section{CONTRIBUTIONS BEFORE 1970}

Following the theory of friction based on asperity contact by Bowden and Tabor (1942), research was intensified in understanding what happens in the junctions at the asperity contacts and how the real area of contact develops. Based on slip-line analysis, Green (1954a,1954b) studied the stress fields associated with different wedge shaped joints. Fig. 1a shows an illustration of a joint, and Fig. 1b shows an example of one of Green's slip-line fields. Both strong (as in Fig. 1b) and weak joints were analyzed and experimental validation of the assumed deformation fields was provided by relative movement between wedges of plasticine and mild steel. Plasticine against plasticine was used to simulate similar surfaces in contact, and mild steel against plasticine was used to simulate a hard surface in contact with a softer surface, which is the typical situation in metal forming. In analysis of junction growth upon relative sliding, Tabor (1959) extended the theory of asperity flattening to include the increase of real contact area due to reduction of the yield pressure by the imposed shear stress upon relative sliding. Shaw et al. (1960) discussed the development of the real area of contact in metal forming processes and suggested a smooth transition between the already accepted linear increase at low normal pressures and full contact area at high normal pressures. The same transition applies for the frictional stress between tool and workpiece. Shaw et al. (1960) provided experimental evidence for the smooth transition by a 
modified Brinell hardness test. The transition can be attributed to subsurface deformation and interaction between the deformation fields of the asperities. It was already mentioned by Bowden and Tabor (1942) that friction cannot be regarded as a pure surface effect because plastic bulk deformation influences the formation of contact area.

Additional weight to this statement was later given by Greenwood and Rowe (1965) and Fogg (1967-1968). Greenwood and Rowe (1965) showed experimentally by compression tests of cylinders with different height to diameter ratios that asperity flattening increases with surface expansion. Fogg (1967-1968) showed experimentally that bulk straining results in larger contact area at constant nominal normal pressure in an apparatus illustrated in Fig. 2a. Fogg explained it by the tangential tensile stresses reducing the yield pressure necessary to flatten the asperities similar to the effect of shear stress as explained by Tabor (1959). The study by Fogg had focus on stretch forming, where the sheet material experiences elongation at normal pressures not resulting in full contact area. The reduction of yield pressure was supported by analysis of effective hardness under different tangential loading, e.g. under biaxial stretching at the bottom of a deep drawing operation as illustrated in Fig. 2 b.

\section{CONTRIBUTIONS IN THE 1970S}

A great deal of the research in the 1970s was focused on theoretical determination of the real contact area at high normal pressures, where individual asperity deformation no longer prevails. The focus on the real area of contact was further justified at the beginning of the decade by Kasuga (1971), who proved that friction is proportional to the real contact area at both low and high normal pressure. A common assumption was to neglect bulk deformation except for the subsurface layers, where interaction between asperities takes place. Pullen and Williamson (1972) stated a lower bound to the real area of contact by simple analytical assumptions to the asperity deformation. The analytical expression was in good agreement with their experimental results 
over a wide range of normal pressures covering the transition zone between low and high normal pressures. Wanheim (1973) suggested a slip-line solution inspired by plane strain extrusion for theoretical calculation of the real contact area from low to high normal pressures and presented validation by experiments. Wanheim et al. (1974) extended the slip-line solution to account for frictional sliding (Fig. 3a) and presented real contact area (Fig. 3b) and frictional stress (Fig. 3c) as function of normal pressure for different amounts of friction on the flattened plateaus. The friction stress was assumed proportional to the real contact area ratio and the shear flow stress with the proportionality factor being the friction factor between tool and workpiece in the real contact. The model was verified by Bay and Wanheim (1976) in controlled, high pressure sliding contact experiments between model asperities and a plane tool surface. The effect of trapped lubricant was studied by Nellemann et al. (1977), the resulting surface roughness and average effective strain of the deformed asperities were predicted by Bay et al. (1975), and the effect of asperities on asperities was analyzed by Steffensen and Wanheim (1977). Wanheim and Bay (1978) gave an overview of the model.

At the end of the decade, Challen and Oxley (1979) proposed three slip-line models accounting for rubbing (Fig. 4a), wear (Fig. 4b) and cutting (Fig. 4c) and predicted on this basis the three regimes of asperity deformation depending on the asperity angle between a hard and a soft asperity and their mutual friction factor (Fig. 4d).

\section{CONTRIBUTIONS IN THE 1980S}

At the threshold of the 1980s, Wanheim and Abildgaard (1980) suggested plastic waves as a mechanism for friction and showed by a slip-line analysis the influence of tool roughness on apparent friction. Fig. 5 shows the apparent friction factor versus the asperity angle with the real friction factor in the tool-workpiece interface as a parameter. Luo et al. (1984) studied the plastic wave phenomena by upper bound solutions, and Bin and Luo (1988) applied the emerging FEM in their study to predict strain distributions and apparent friction. These groups also proved the 
existence of the phenomena by experiments. Challen et al. (1984a,1984b) studied by slip-line analyses and experiments the relative sliding between a hard tool with wedge shaped grooves and a soft material. The development of the filling of the hard tool and the transition between plastic waves and wear were studied. Fig. 6 shows examples of the slip-line fields used by Challen and Oxley (1984b) in the study of filling from a low degree (Fig. 6a) to almost complete filling (Fig. 6b). Asperity flattening was still a main research topic due to the lack of theoretical modeling involving bulk deformation besides the interaction between asperities. Sheu and Wilson (1983) presented an upper bound solution for the asperity flattening under bulk deformation by analogy with flat hardness indentations. Later refinements of the upper bound solution, Wilson and Sheu (1988), allowed matching the theoretical results with rolling experiments. Sutcliffe (1988) suggested the slip-line field in Fig. 7a for theoretical determination of the real contact area in asperity flattening under bulk deformation. The slip-line field consists of the combination of the slip-line fields for indentation into a thick plate and uniform deformation. Solution of the field together with geometrical consideration of triangular asperities resulted in a differential equation for the real contact area as function of normal pressure, longitudinal strain and flank angle. Fig. $7 \mathrm{~b}$ shows the resulting set of curves for flank angles of $20^{\circ}$. Makinouchi et al. (1988) simulated asperity flattening by an FE model including three asperities with free sides (Fig. 8a), where strain hardening was included in the analysis. They were able to match experimental and simulated real contact area as function of the compression in terms of the height reduction (Fig. 8b). Ike and Makinouchi (1990) extended the model to include five asperities and also presented a single asperity with periodic boundary conditions. They included longitudinal stresses to extend the original model from being with only free sides and were thereby able to analyze different levels of subsurface deformation with their models.

\section{CONTRIBUTIONS IN THE 1990S}

Wilson $(1991)$ extended the use of previous work $(1983,1988)$ to include more complex surface contact including a rough tool in relative sliding with a softer workpiece material. Korzekwa et al. (1992) applied numerical modeling by FEM to simulate asperity deformation under bulk 
deformation in 3D (Fig. 9a). They analyzed the influence of different straining directions relative to the direction of the long 2D asperities. Fig. 9b shows an example of predicted real area of contact as function of bulk effective strain for three different loading directions, where $\phi=0$ corresponds to plane strain tension perpendicular to the $2 \mathrm{D}$ asperities, $\phi=2.034$ is close to uniaxial tension parallel to the $2 \mathrm{D}$ asperities, and $\phi=2.678$ is close to uniaxial compression perpendicular to the $2 \mathrm{D}$ asperities. They additionally showed the possibility of simulating asperity flattening with a 3D layout of asperities.

Saha and Wilson (1994) presented experimental results from a friction test, where the workpiece strip material is simultaneously under normal pressure and in-plane elongation. Depending on the strip material, they experienced both increasing and decreasing friction with increasing elongation, and they explained it by dominant asperity flattening in the former case and dominant roughening due to coarse grains in the latter case. A new view of friction modeling was presented by Carter (1994), who suggested that the modeling should be based on the deviatoric component of the interfacial normal pressure rather than the total normal pressure which was commonly used and still is. Carter's argument was that when the plastic deformation itself is independent of the hydrostatic pressure, the friction modeling by the adhesion theory should also be independent of the hydrostatic pressure. At the end of the decade, Sutcliffe (1999) proposed theoretical modeling of asperity flattening under bulk deformation taking into account different wavelengths of the asperities. Sutcliffe was able to calculate the real area of contact as well as the changing roughness based on a model with asperities with two different wavelengths and validated the predictions by experiments.

\section{CONTRIBUTIONS SINCE 2000}

Developments of numerical algorithms during the past decades made the use of numerical simulations continuously growing since the turn of the millennium. Zhang et al. (2003) demonstrated numerical simulation of local tool-workpiece contact to establish a local friction model based on specific tool and workpiece roughnesses and applied the model in simulation of 
deep drawing. Hol et al. $(2012,2015)$ presented multi-scale simulation of the frictional effects in sheet metal forming, where surface asperities were modeled by bars and statistical parameters as illustrated in Fig. 10a. The asperity flattening was modeled by energy balance taking into account the interaction between the deformable bars. Local friction coefficients were estimated based on the real surface topographies (Fig. 10b) through the analytical expressions taking in the statistical surface parameters. Asperity flattening under normal as well as tangential loading was included along with the local material flow near rough tool surfaces. The local information on friction coefficients were then supplied to a full scale simulation of sheet metal forming (Fig. 10c).

Wang et al. (2014) presented a testing apparatus capable of flatten asperities under bulk deformation. They also showed numerical simulation of their five-asperity test with an example of the resulting real contact area as function of effective bulk plastic strain (Fig. 11a). They proposed a new friction model as shown in Fig. 11b, where a critical normal pressure separates the two regimes defined by Amontons-Coulomb's law at low normal pressures and the constant friction model at high normal pressures. They provide an expression for the critical pressure and suggest an expression linking the friction coefficient $\mu$ and the friction factor $m$, such that it is enough to estimate the friction coefficient at low pressures for determining the full friction model. They take into account the fact that the flattened asperities are not in full contact with the tool due to higher order real contact areas as described by Steffensen and Wanheim (1977) and roughening of the surface due to grain rotation upon elongation. Fig. 11c shows the friction model by Wang et al. (2014) together with experimental data. In a later contribution, Wang et al. (2015) included strain hardening in their analysis of asperity flattening. Nielsen et al. (2016) focused on determining the real contact area ratio as function of normal pressure and longitudinal bulk strain for strain hardening materials by experiments and FE simulations. Results for aluminum 1050 are shown in Fig. 12.

\section{CONCLUSIONS}


Having presented a subjective overview of the most important contributions to friction modeling over the last 80 years, it seems to be necessary to still work on full mapping of the real contact area as function of normal pressure, bulk deformation, material properties and surface conditions. It is also necessary to work closer to the real sizes of asperities rather than model asperities, and finally, it is expected that existing FE codes will more commonly be enhanced by new developments of friction modeling in the future.

\section{ACKNOWLEDGEMENTS}

The authors would like to thank The Danish Council for Independent Research (Grant number: DFF-1335-00230) for financial support.

\section{REFERENCES}

Bay, N., Wanheim, T., Petersen, A.S., 1975. Ra and the average effective strain of surface asperities deformed in metal working processes. Wear 33, 77-84.

Bay, N., Wanheim, T., 1976. Real area of contact and friction stress at high pressure sliding contact. Wear 38, 201-209.

Bin, F., Luo, Z.-J., 1988. Finite element simulation of the friction mechanism in plastic-working technology. Wear 121, 41-51.

Bowden, F.P., Tabor, D., 1942. Mechanism of metallic friction. Nature 50(3798), 197-199.

Carter, W.T., 1994. A model for friction in metal forming. Transactions of the ASME 116, 8-13. Challen, J.M., Oxley, P.L.B., 1979. An explanation of the different regimes of friction and wear using asperity deformation models. Wear 53, 229-243.

Challen, J.M., Mclean, L.J., Oxley, P.L.B., 1984a. Plastic deformation of a metal surface in sliding contact with a hard wedge: its relation to friction and wear. Proceedings of the Royal Society of London. Series A, Mathematical and Physical Sciences 394, 161-181.

Challen, J.M., Oxley, P.L.B., 1984b. A slip line field analysis of the transition from local asperity contact to full contact in metallic sliding friction. Wear 100, 171-193. 
Ernst, H., Merchant, M.E., 1940. Surface friction between metals - a basic factor in the metal cutting process, In Proceedings of the Special Summer Conference on Friction and Surface Finish, MIT Press, Cambridge MA, pp. 76-101.

Fogg, B., 1967-1968. Preliminary study of the influence of stress and deformation in the substrate on junction growth and friction. Proceedings of the Institution of Mechanical Engineers 182(Pt/3K), 152-161.

Green, A.P., 1954a. The plastic yielding of metal junctions due to combined shear and pressure. Journal of the Mechanics and Physics of Solids 2, 197-211.

Green, A.P., 1954b. Friction between unlubricated metals: a theoretical analysis of the junction model. Proceedings of the Royal Society A 228(1173), 191-206.

Greenwood, J.A., Rowe, G.W., 1965. Deformation of surface asperities during bulk plastic flow. Journal of Applied Physics 36(2), 667-668.

Hol, J., Cid Alfaro, M.V., de Rooij, M.B., Meinders, T., 2012. Advanced friction modeling for sheet metal forming. Wear 286-287, 66-78.

Hol, J., Meinders, V.T., de Rooij, M.B., van den Boogaard, A.H., 2015. Multi-scale friction modeling for sheet metal forming: The boundary lubrication regime. Tribology International 81, 112-128. Holm, R., 1938. Über die auf die wirkliche Berührungsfläche bezogene Reibungskraft, Veröff., Siemens-Werken 17, 38-42.

Ike, H., Makinouchi, A., 1990. Effect of lateral tension and compression on plane strain flattening processes of surface asperities lying over a plastically deformable bulk. Wear 140, 17-38. Kasuga, Y., 1971. Boundary lubrication under high contact pressure (in Japanese). Lubrication 16(12), 748-758.

Korzekwa, D.A., Dawson, P.R., Wilson, W.R.D., 1992. Surface asperity deformation during sheet forming. International Journal of Mechanical Sciences 34(7), 521-539.

Luo, Z.J., Tang, C.R., Avitzur, B., van Tyne, C.J., 1984. A model for simulation of friction phenomenon between dies and workpiece. Applied Mathematics and Mechanics 5(3), 1297-1307. Makinouchi, A., Ike, H., Murakawa, M., Koga, N., 1988. A finite element analysis of flattening of surface asperities by perfectly lubricated rigid dies in metal working processes. Wear 128, 109122. 
Nellemann, T., Bay, N., Wanheim, T., 1977. Real area of contact and friction stress - the role of trapped lubricant. Wear 43, 45-53.

Nielsen, C.V., Martins, P.A.F., Bay, N., 2016. Modelling of real area of contact between tool and workpiece in metal forming processes including the influence of subsurface deformation. CIRP Annals - Manufacturing Technology 65, 261-264.

Orowan, E., 1943. The calculation of roll pressure in hot and cold flat rolling. Proceedings of the Institution of Mechanical Engineers 150(1), 140-167.

Pullen, J., Williamson, J.B.P., 1972. On the plastic contact of rough surfaces. Proceedings of the Royal Society of London. Series A, Mathematical and Physical Sciences 327, 159-173.

Saha, P.K., Wilson, W.R.D., 1994. Influence of plastic strain on friction in sheet metal forming. Wear 172, 167-173.

Shaw, M.C., Ber, A., Mamin, P.A., 1960. Friction characteristics of sliding surfaces undergoing subsurface plastic flow. Journal of Basic Engineering, 342-346.

Sheu, S., Wilson, W.R.D., 1983. Flattening of workpiece asperities in metalforming. In Proceedings of the 11th North American Manufacturing Research Conference, pp. 172-178.

Steffensen, H., Wanheim, T., 1977. Asperities on asperities. Wear 43, 89-98.

Sutcliffe, M.P.F., 1988. Surface asperity deformation in metal forming processes. International Journal of Mechanical Sciences 30(11), 847-868.

Sutcliffe, M.P.F., 1999. Flattening of random rough surfaces in metal-forming processes. Journal of Tribology 121, 433-440.

Tabor, D., 1959. Junction growth in metallic friction: the role of combined stresses and surface contamination. Proceedings of the Royal Society of London. Series A, Mathematical and Physical Sciences 251, 378-393.

Wang, Z.G., Yoshikawa, Y., Suzuki, T., Osakada, K., 2014. Determination of friction law in dry metal forming with DLC coated tool. CIRP Annals - Manufacturing Technology 63, 277-280.

Wang, Z.G., Komiyama, S., Yoshikawa, Y., Suzuki, T., Osakada, K., 2015. Evaluation of lubricants without zinc phosphate precoat in multi-stage cold forging. CIRP Annals - Manufacturing Technology 64, 285-288.

Wanheim, T., 1973. Friction at high normal pressure. Wear 25, 225-244. 
Wanheim, T., Bay, N., Petersen, A.S., 1974. A theoretically determined model for friction in metal working processes. Wear 28, 251-258.

Wanheim, T., Bay, N., 1978. A model for friction in metal forming processes. Annals of the CIRP 27, 189-194.

Wanheim, T., Abildgaard, T., 1980. A mechanism for metallic friction. In Proceedings of the 4th International Conference on Production Engineering, Tokyo, pp. 122-127.

Wilson, W.R.D., Sheu, S., 1988. Real area of contact and boundary friction in metal forming. International Journal of Mechanical Sciences 30(7), 475-489.

Wilson, W.R.D., 1991. Friction models for metal forming in the boundary lubrication regime. Journal of Engineering Materials and Technology 113(61), 60-68.

Zhang, S., Hodgson, P.D., Cardew-Hall, M.J., Kalyanasundaram, S., 2003. A finite element simulation of micro-mechanical frictional behavior in metal forming. Journal of Materials Processing Technology 134, 81-91. 
Figures

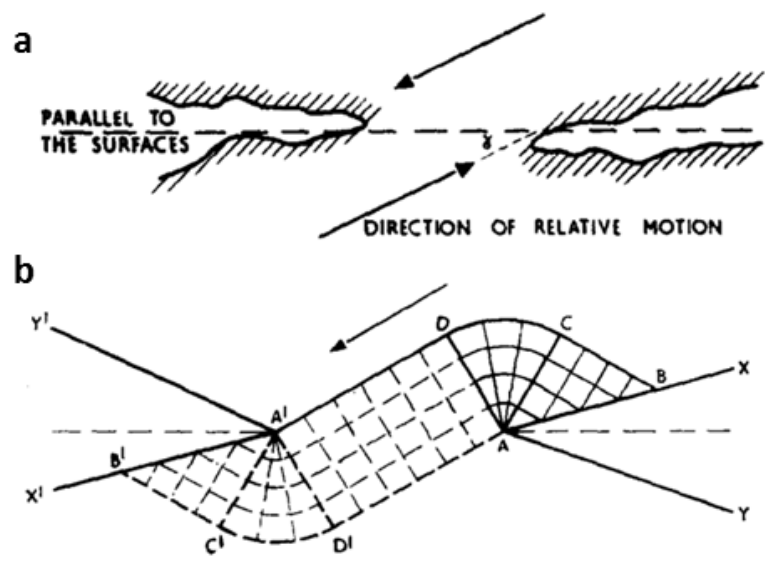

Figure 1. Illustrations by Green (1954a) showing (a) strong junction in relative sliding and (b) the associated slip-line field for theoretical analysis.
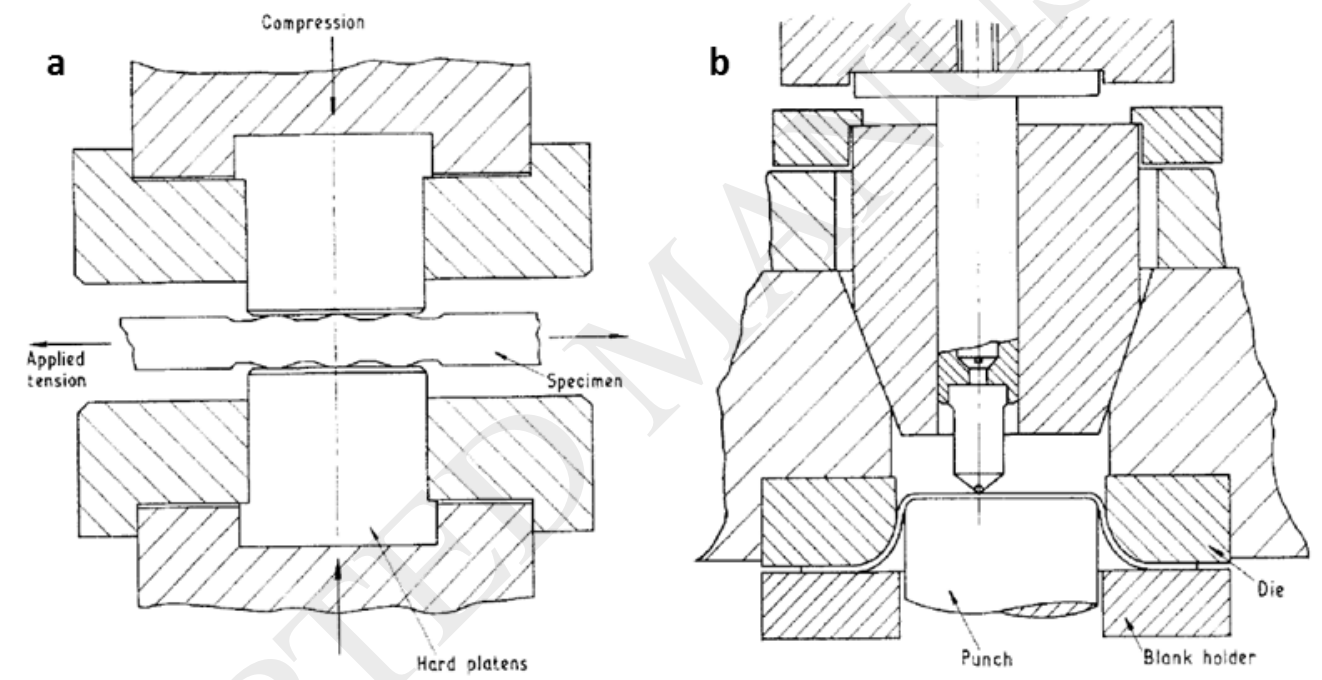

Figure 2. Illustrations by Fogg (1967-1968) showing (a) compression of asperities under tangential tensile loading and (b) hardness indentation under biaxial stretching.
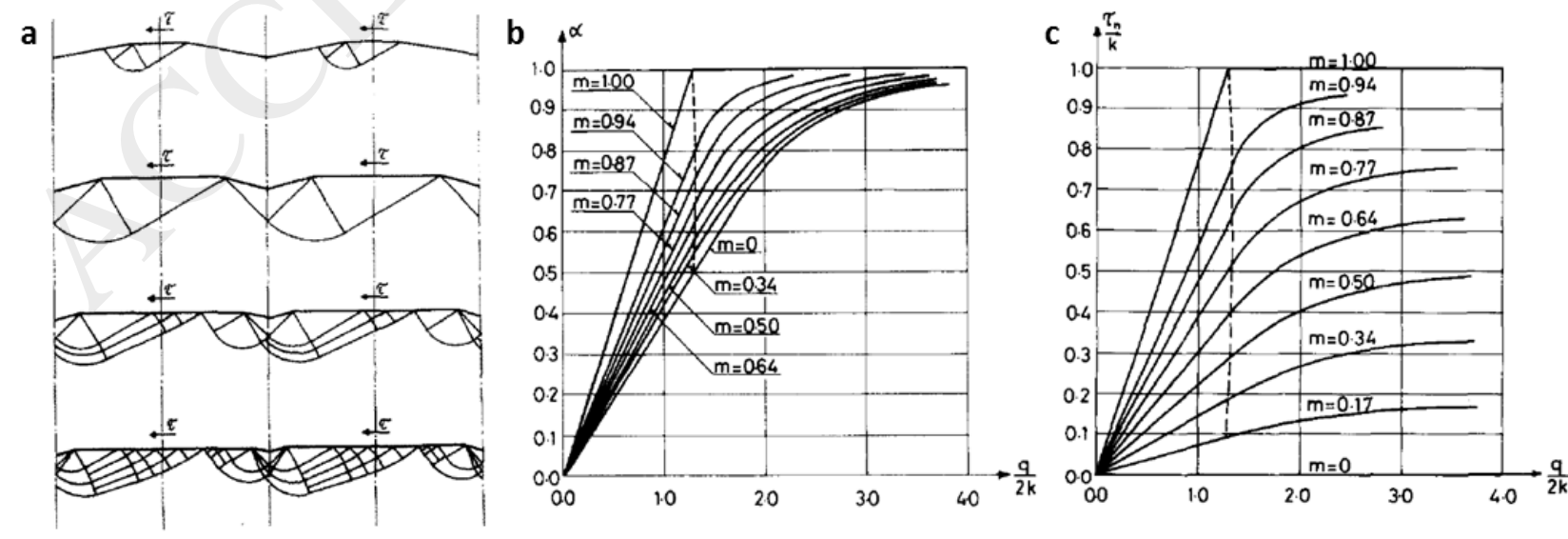
Figure 3. Illustrations by Wanheim et al. (1974) showing (a) proposed slip-line field for asperity flattening under frictional sliding; (b) theoretical real contact area for different amounts of friction on the flattened plateaus as function of normal pressure, and (c) the corresponding frictional sliding.
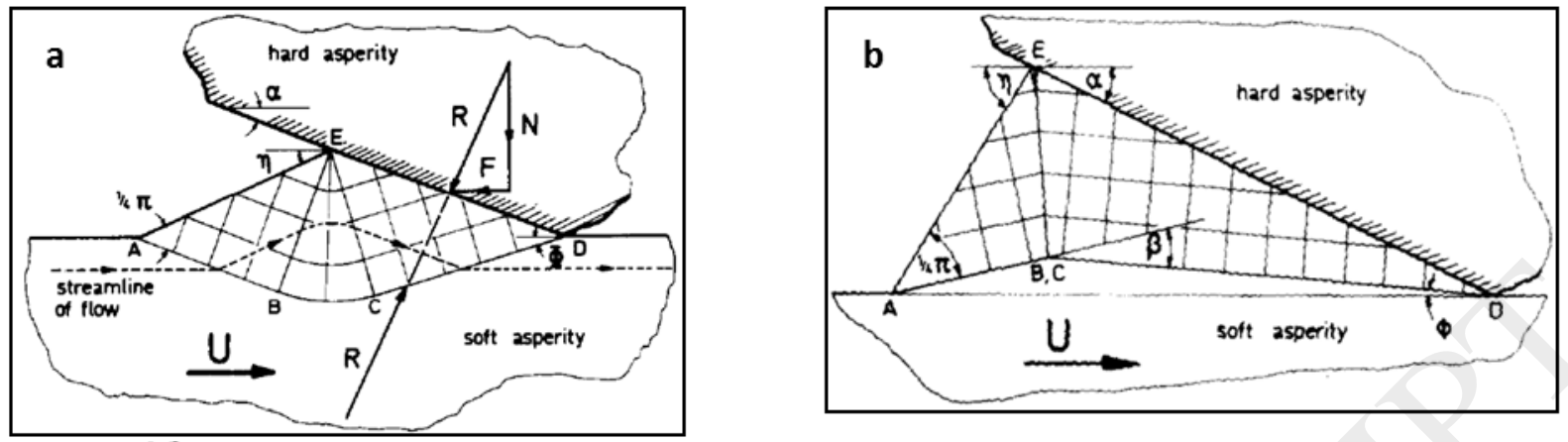

d

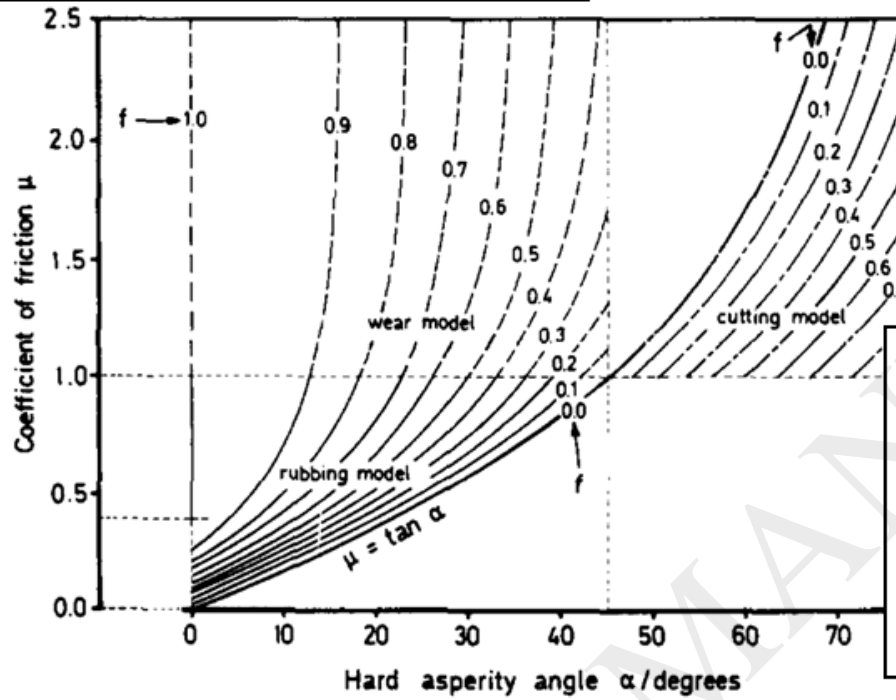

0.1 i i
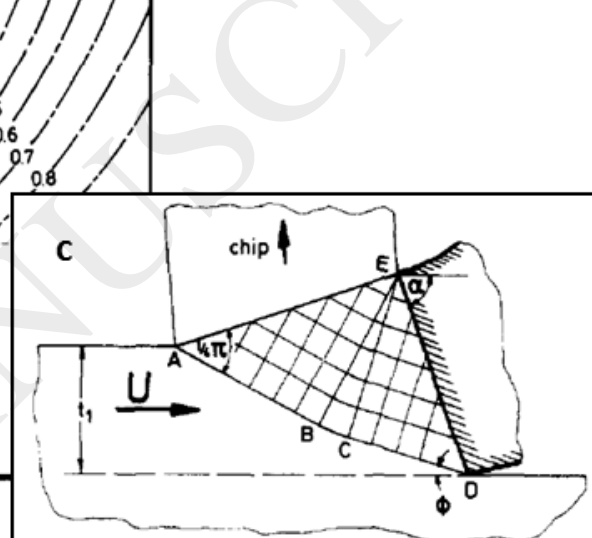

Figure 4. Different regimes by Challen and Oxley (1979). The three regimes were analyzed by slip-line fields for (a) rubbing, (b) wear and (c) cutting, where the latter is here exemplified by the case of restricted contact. The diagram (d) shows the three regimes as function of asperity angle and friction. 


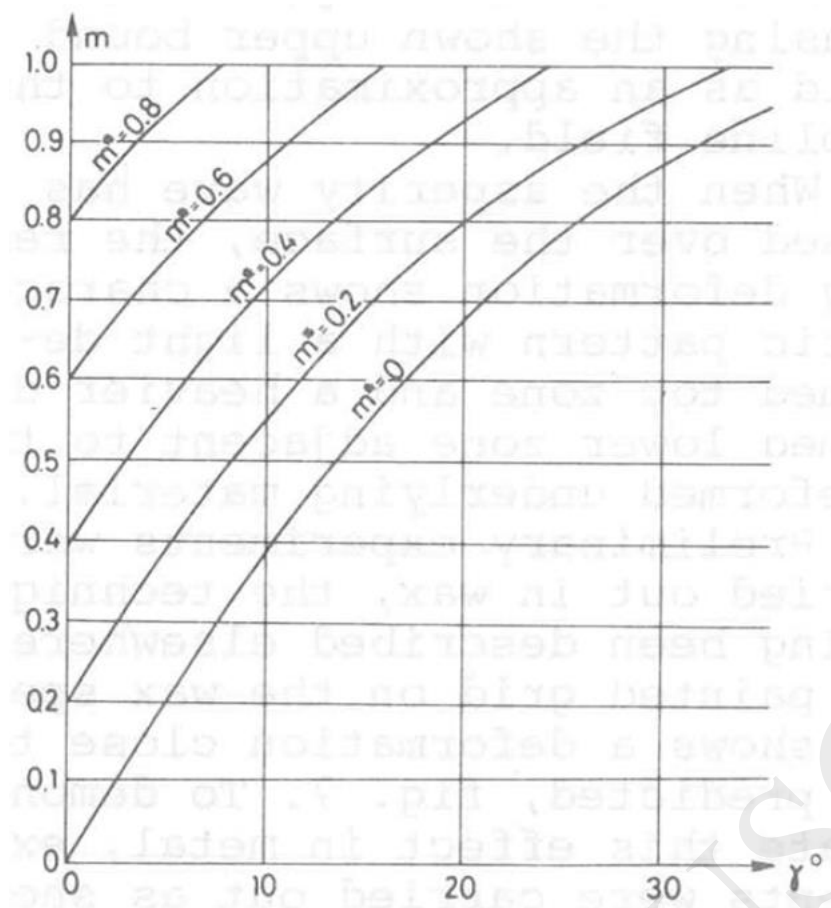

Fig. 5. Apparent friction factor $m$ versus asperity slope $\gamma$ with real friction factor $m^{*}$ as parameter by Wanheim and Abildgaard (1980).

a

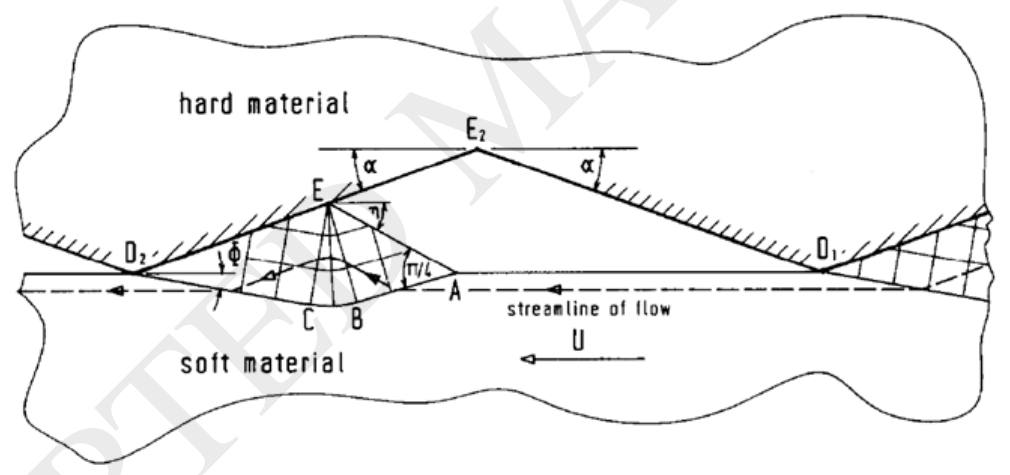

b

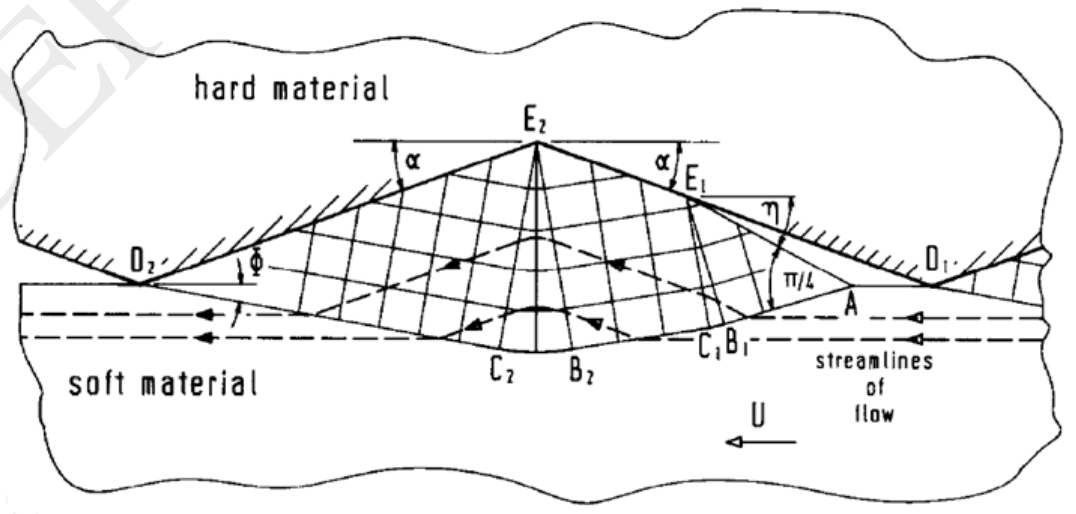

Figure 6. Slip-line fields by Challen and Oxley (1984b) for the analysis of the transition between (a) local and (b) almost full contact during frictional sliding. 

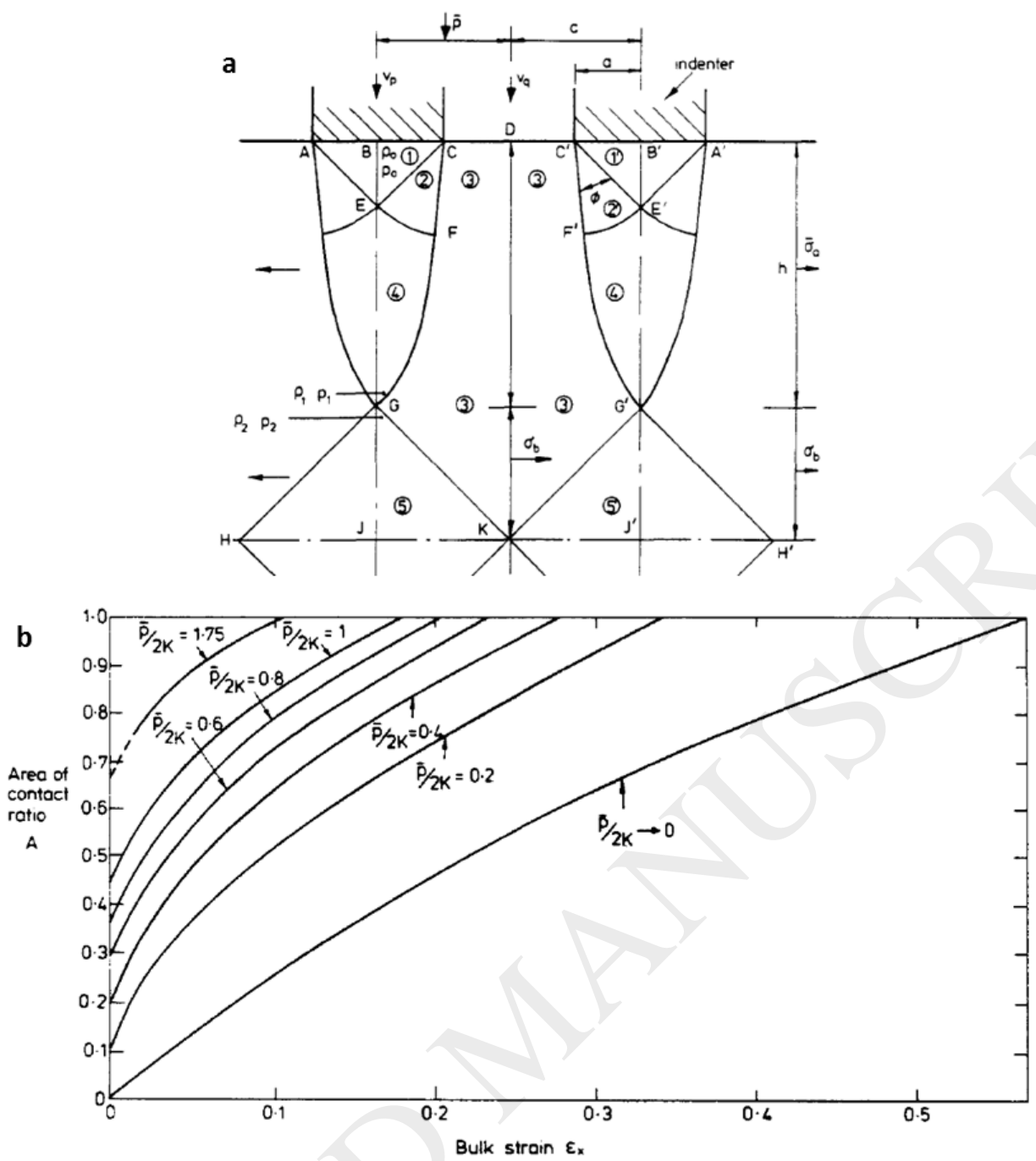

Figure 7. Illustrations by Sutcliffe (1988) showing (a) a combined slip-line field for hardness indenters and uniform deformation for theoretical analysis of asperity flattening with subsurface deformation; (b) resulting contact area ratio for different normal pressures as function of longitudinal bulk strain with asperity flank angles of $20^{\circ}$. 
a

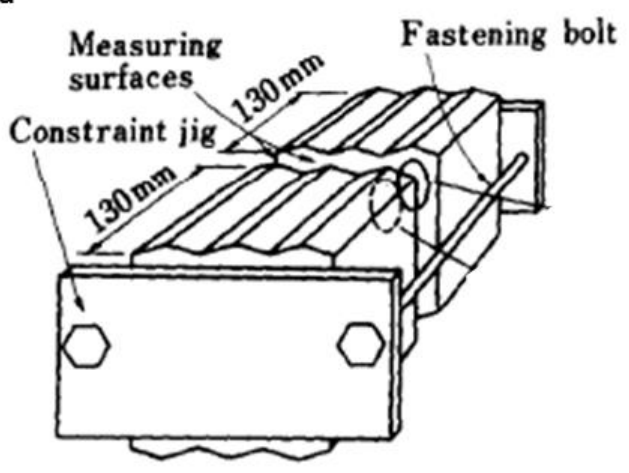

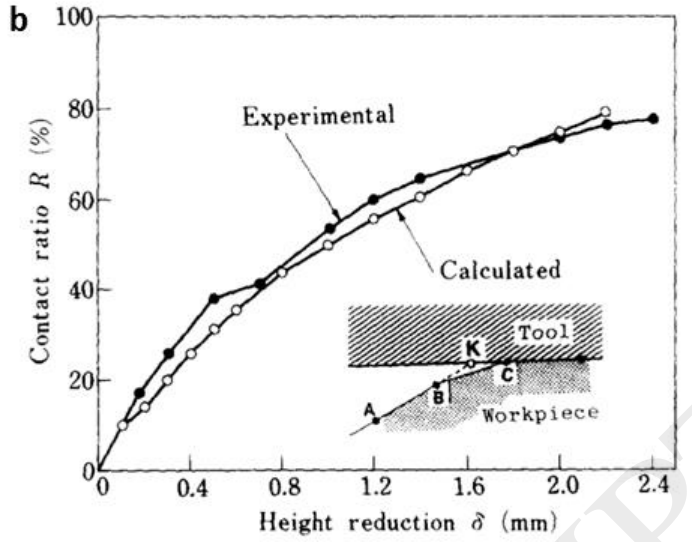

Figure 8. Finite element analysis of asperity flattening by Makinouchi et al. (1988) illustrated by (a) the three-asperity model used for simulation and experimentation and (b) the comparison between experimental and simulated contact area ratio as function of height reduction.

a

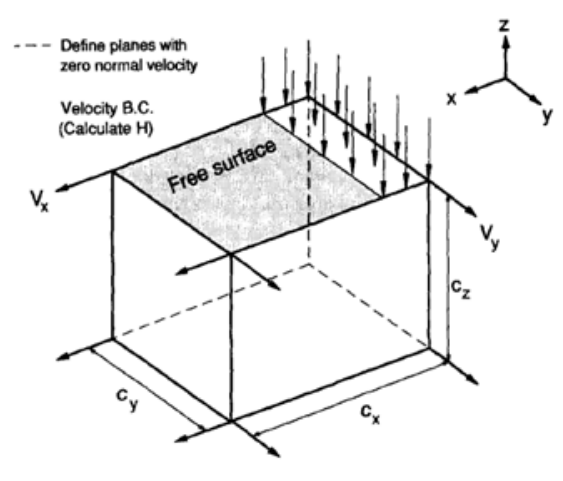

b

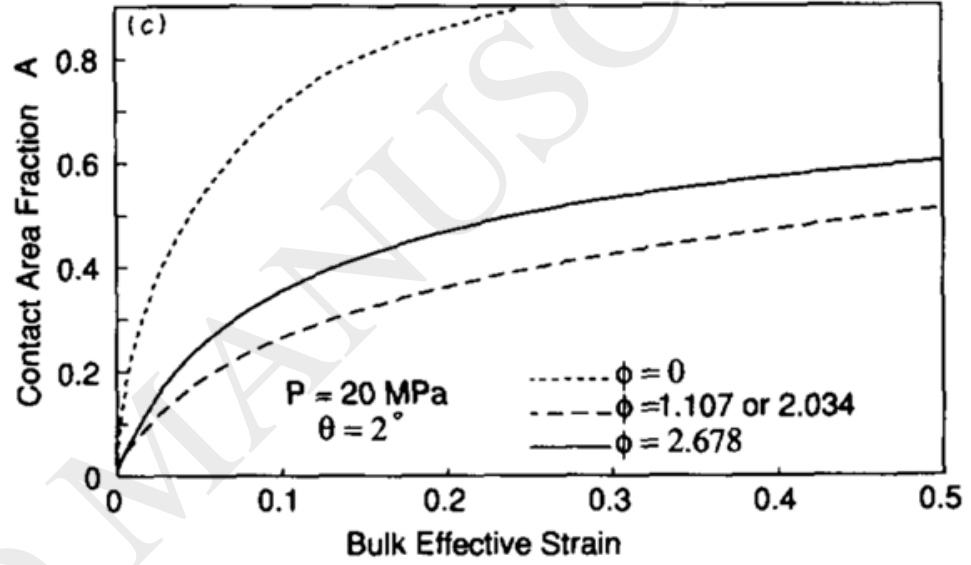

Figure 9. Three-dimensional finite element analysis of asperity flattening by Korzekwa et al. (1992), where (a) is the boundary value problem to be solved and $(b)$ is an example of the results by contact area ratio as function of bulk effective strain and straining direction perpendicular to the normal loading. 


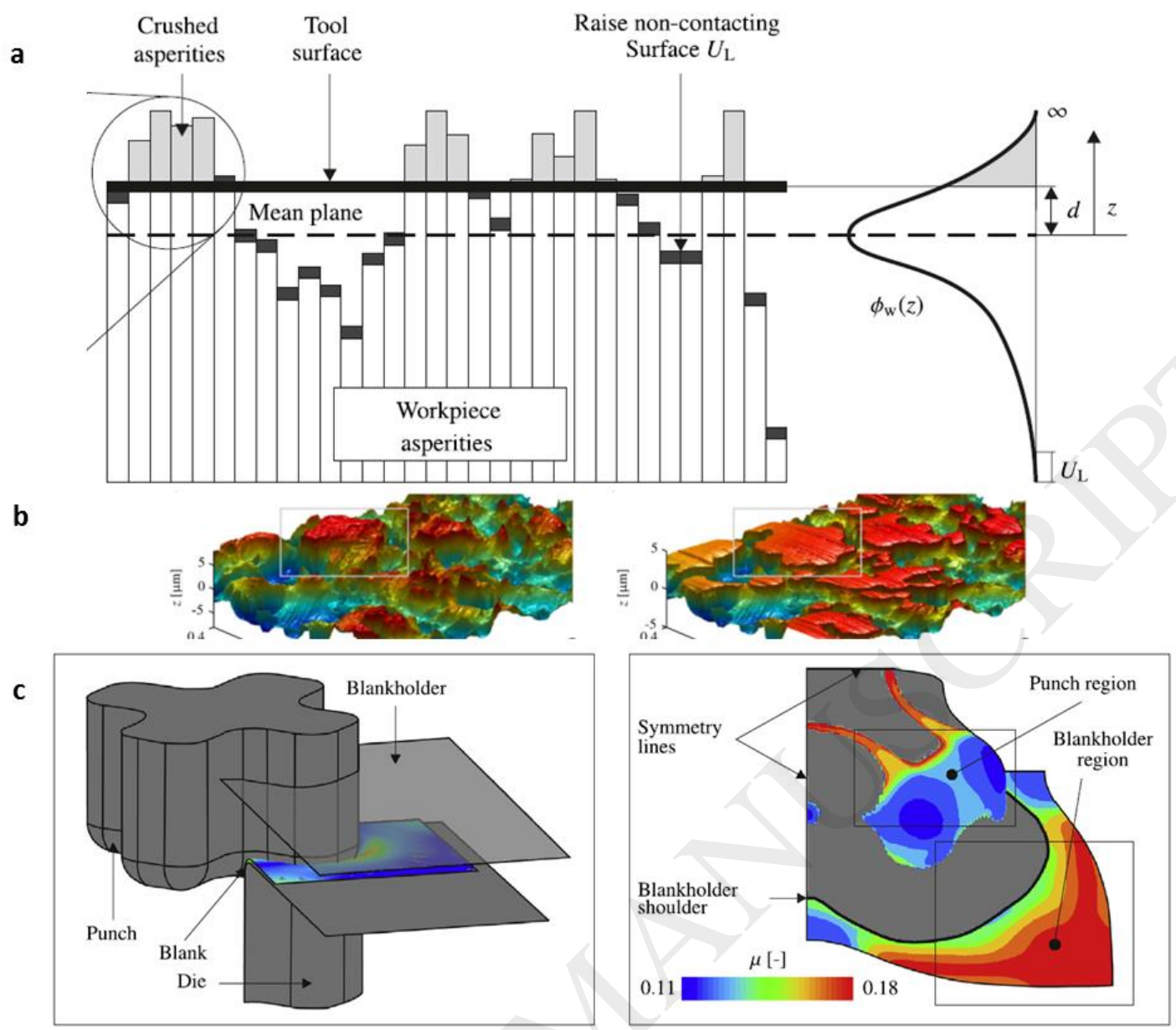

Figure 10. Friction modeling by Hol et al. (2015). (a) Representation of workpiece surface asperities by bars and statistical parameters for calculation of asperity flattening. (b) Measured surface and indication of surface deformation. (c) Simulation of cross-die product and locally predicted friction coefficients.

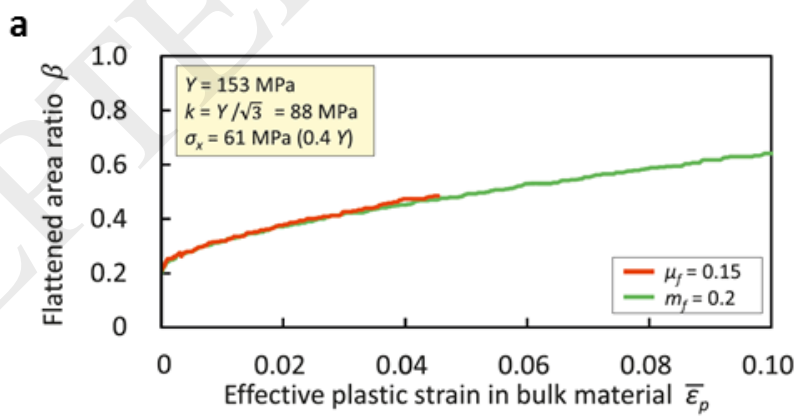

b

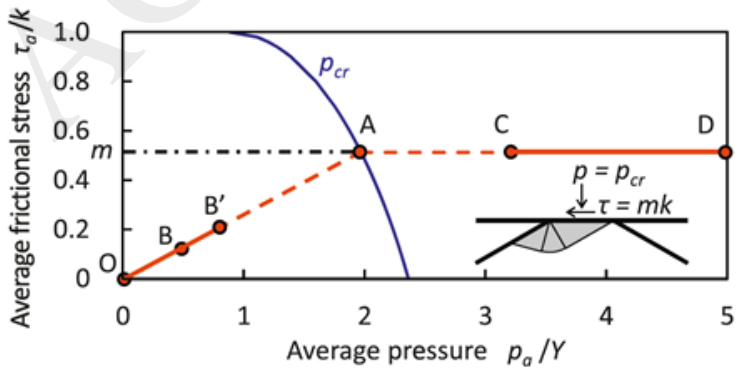

C

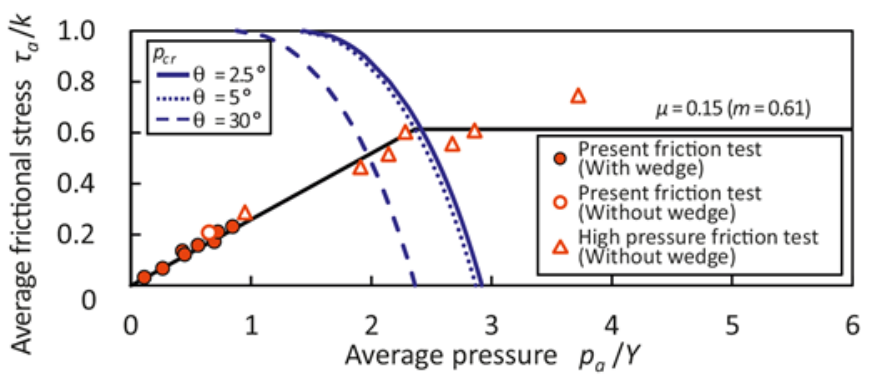


Figure 11. Friction law by Wang et al. (2014) illustrated by (a) simulated real contact area as function of effective strain, (b) friction law by combining Amontons-Coulomb's model and constant friction, and (c) friction law with experimental data compared to the theoretical model with varying wedge slope.

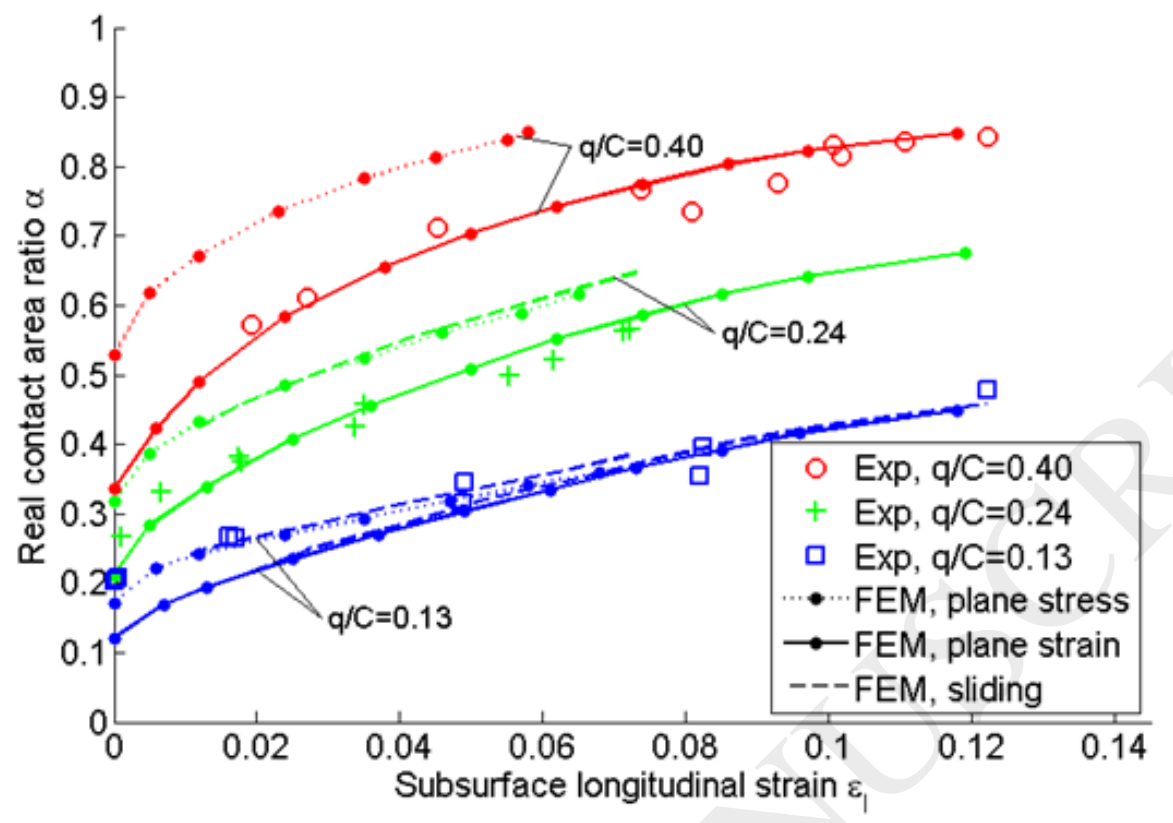

Figure 12. Simulated and experimental real area of contact at different normal pressures as function of subsurface longitudinal strain by Nielsen et al. (2016). 